\title{
Are We Ignoring Supply Shocks? A Proposal for Monitoring Cyclical Fluctuations
}

\section{Carolina Pagliacci}

April 2016

\section{Research Papers}




\section{ICEMLA}

Research

\section{ARE WE IGNORING SUPPLY SHOCKS?}

A PROPOSAL FOR MONITORING CYCLICAL FLUCTUATIONS

\section{Author:}

Carolina Pagliacci

First edition, 2016

C 2016 Center for Latin American Monetary Studies (CEMLA)

Durango 54, Colonia Roma Norte, Delegación Cuauhtémoc, 06700 México D. F.,

Mexico

E-mail:publicaciones@cemla.org

http://www.cemla.org

The views expressed herein are those of the authors and do not necessarily reflect those of the cemla or its members. 


\title{
Are We Ignoring Supply Shocks?

\author{
A Proposal for Monitoring \\ Cyclical Fluctuations
}

Carolina PagliacCi, Banco Central de Venezuela

\begin{abstract}
Senior Researcher of the Economic Research Office at the Banco Central de Venezuela. This paper received the financial support of the Centro de Estudios Monetarios Latinoamericanos (CEMLA) through the part-time at distance internship modality. This paper has also benefited from the comments of participants at the seminars of Central Bank of Venezuela and CEMLA, especially Daniel Barráez, Alberto Ortiz, Kólver Hernández, Horacio Aguirre, Jorge Hernández, Nora Guarata, León Fernández and Paul Castillo. Lorena Barreiro provided exceIlent research assistance.
\end{abstract}

cpagliac@bcv.org.ve

\section{ABSTRACT}

Although there are several mechanisms within modern theoretical models acknowledging that supply shocks can account for an important part of output fluctuations, even in the short-run, policy practitioners continue endorsing the idea that only demand shocks explain them. This article provides firstly, empirical evidence showing that supply shocks are much more important for explaining output (and price) fluctuations than what the common wisdom indicates; secondly, a more agnostic implementation of the Blanchard-Quah type of structural analysis that focuses on policy evaluation. Empirical evidence on several Latin American countries and the United States shows that the share of output variance explained by supply shocks in the short-run is substantial. Results are based on the identifi- cation of supply and demand shocks in the context of a bi-variate structural vAR (SVAR) that uses inflation information and sign restrictions for short-run identification. The identification strategy uses the notion that supply and demand disturbances can be distinguished by the direction of their effects on output and prices. For policy analysis purposes, we suggest computing the historical decomposition of output growth for each type of shock and propose two-related new indicators that should guide monetary policy interventions more adequately than traditional output gaps.

Keywords: Cyclical fluctuation, structural demand and supply identification, sign restriction identification.

JEL codes: E32, E31, C32. 


\title{
Are we ignoring supply shocks? A proposal for monitoring cyclical fluctuations
}

\author{
Carolina Pagliacci ${ }^{\&}$
}

\begin{abstract}
Although there are several mechanisms within modern theoretical models acknowledging that supply shocks can account for an important part of output fluctuations, even in the short-run, policy practitioners continue endorsing the idea that only demand shocks explain them. This article provides firstly, empirical evidence showing that supply shocks are much more important for explaining output (and price) fluctuations than what the common wisdom indicates; secondly, a more agnostic implementation of the Blanchard-Quah type of structural analysis that focuses on policy evaluation. Empirical evidence on several Latin American countries and the United States shows that the share of output variance explained by supply shocks in the short-run is substantial. Results are based on the identification of supply and demand shocks in the context of a bi-variate structural VAR (SVAR) that uses inflation information and sign restrictions for short-run identification. The identification strategy uses the notion that supply and demand disturbances can be distinguished by the direction of their effects on output and prices. For policy analysis purposes, we suggest computing the historical decomposition of output growth for each type of shock and propose two-related new indicators that should guide monetary policy interventions more adequately than traditional output gaps.
\end{abstract}

Keywords: cyclical fluctuation, structural demand and supply identification, sign restriction identification.

JEL codes: E32, E31, C32.

\& Senior Researcher of the Economic Research Office at the Central Bank of Venezuela, email: cpagliac@bcv.org.ve, phone: +58212-8015919, postal address: av. Urdaneta con esq. Carmelitas, edf. Sede, piso 2, Caracas 1010, Venezuela.This paper received the financial support of the Centro de Estudios Monetarios Latinoamericanos (Cemla) through the part-time at distance internship modality. This paper has also benefited from the comments of participants at the seminars of Central Bank of Venezuela and Cemla, especially Daniel Barráez, Alberto Ortiz, Kólver Hernández, Horacio Aguirre, Jorge Hernández, Nora Guarata and Paul Castillo. Lorena Barreiro provided excellent research assistance. 


\section{Introduction}

As stated by Basu and Fernald (2009), policy practitioners appear to assume that potential output is a smooth trend. For some analysts, this is the case because potential output is related to a "steady-state measure" for output growth. For others, this smoothness of potential output reflects the notion that factor supplies and technology do not change abruptly in time. This is consistent with the traditional Keynesian Okun's law that states that potential output is the "maximum production without inflationary pressures". Under this framework, the difference between the actual output and its potential measure is defined as the output gap, which basically reflects changes in demand pressures. Therefore, cyclical (short-run) fluctuations of output and inflation are exclusively related to the fluctuations in output gap and the occurrence of aggregate demand shocks.

In the quest for easily implementing the above wisdom, practitioners are prone to confound the statistical trend of output with the notion of potential output, and the difference between actual output and its trend with the notion of output gap. ${ }^{1}$ As a result, it is commonly assumed that supply-related shocks only cause changes in the trend, and do not affect output in the short-run. Likewise, it is presumed that demand shocks are long-run neutral for output, since their effect vanish over time. On this discussion, and related to the empirical implementation of that wisdom, the work of Blanchard and Quah (1989) provide several important contributions that need to be mentioned. On the one hand, their work is the first to identify "supply versus demand" disturbances instead of "trend versus cycle" shocks. This distinction, supported within the traditional Keynesian framework, provided practitioners with a statistical identification strategy that also had a more sound (structural) economic content. Second, they argue that, since cycle and trend disturbances are theoretically correlated, establishing an adequate distinction between them is rather difficult. This is the case because supply shocks affect both, the business cycle and the trend component of output. Likewise, they state that the trend component should be strictly associated with the theoretical notion of output observed under full flexible prices, a definition difficult to implement on their model.

The empirical evidence found by Blanchard and Quah (1989) on the United States shows that demand shocks explain most of the variance of output in the short-run (more than $80 \%$ ) for most VAR specifications employed. Also, the variance of output in the long-run is exclusively explained by supply shocks since their key identifying assumption is that demand disturbances do not have a permanent effect on output (the long-run neutrality assumption of demand shocks). Therefore, although their identifying restrictions allow supply shocks to have a non-negligible impact on output in the short-run, results at that time did not support this possibility.

\footnotetext{
${ }^{1}$ For a more detailed discussion on how potential output and output gap should be measured in the context of New Keynesian DSGE models, see Basu and Fernald (2009).
} 
As I shall explain later, there are several mechanisms within modern theoretical models supporting the notion that supply shocks can account for an important part of output fluctuations in the short-run. Nonetheless, practitioners seem to have failed to acknowledge such mechanisms and prefer to continue endorsing the idea that only demand shocks explain cyclical fluctuations. In fact, when applying the Blanchard-Quah methodology, papers such as Fuentes, Gredig, and Larraín (2008) assume ex-ante that cyclical fluctuations are exclusively captured by demand shocks. Also, by assuming that supply shocks are related to potential output, these authors identify the output gap as the demand component of output, i.e. the fluctuations of output exclusively caused by the effects of demand shocks.

In this context, the objective of this paper is twofold. On the one hand, convincing practitioners that supply shocks are much more important for explaining fluctuations than what the common wisdom indicates. On the other hand, offering a more agnostic implementation of the structural analysis that focuses on policy evaluation. We provide empirical evidence on several Latin American countries, such as Argentina, Brazil, Chile Colombia, Mexico, Peru, and Venezuela to acknowledge the importance of supply shocks for short-run output fluctuations. ${ }^{2}$ We also add to this sample data on the United States to determine to what extent Blanchard and Quah (1989) results still hold. Our findings show that the share of output variance explained by supply shocks in the short-run is substantial (greater than 50\%) for 5, out of 8 , countries in the sample. We also find that supply shocks explain a sizeable part of the variance of inflation in the short, and the long-run.

These results are based on the implementation of the Blanchard-Quah type of structural methodology that identifies supply and demand shocks. But in our case, the identification strategy is based on a more general notion: supply and demand disturbances can be distinguished by their effect on output and prices. $^{3}$ This identification strategy and the assessment of the effect of both shocks provide practitioners with a more agnostic view on how to interpret cyclical fluctuations. Econometrically, this identification, implemented as short-run sign restrictions on a bi-variate VAR that includes price information (instead of unemployment), also overcomes a criticism found in recent literature to the long-run neutrality of demand shocks. On this respect, Keating (2013) argues that, under certain conditions, demand shocks can in fact have permanent effects on output. ${ }^{4}$ Later in this paper, we show that the persistent effect of demand shocks on output is also observed in our data.

\footnotetext{
2 Contentiously, in these countries, Central Banks' analysts commonly rely on univariate or Hodrick-Prescott (HP) measures of the output gap to deliver their diagnosis of the short-run.

${ }^{3}$ This identification strategy is not new in the literature, but the theoretical motivations for using it have not been explicitly described. We do so in the context of New Keynesian DSGE models in section 2 .

${ }^{4}$ Keating (2013) shows that empirical evidence for the United States and other countries prior to WWI, is inconsistent with the assumption that demand shocks cannot have a permanent effect on output. His claim is based on the comparison between the theoretical assumptions imposed by the Blanchard-Quah identification and the estimated parameters of a statistical model.
} 
For this proposal to have a clear utility for policy analysis, we suggest computing the historical decomposition of output growth and propose tworelated new indicators: the total cyclical fluctuations indicator (TCF) and the good market unbalance indicator (GMU). Since historical decompositions provide the dynamic effects of the realizations of a single structural shock on a variable, we can obtain the supply and the demand components of output respectively. The indicator of total cyclical fluctuations (TCF) is defined as the sum of the supply and demand components of output. A positive (negative) sign of this indicator points out whether the actual variable is growing (falling) above (below) its long-run or steady state value. In other words, the sign of TCF provides the net effect of shocks on output in relation to its long-run rate. When supply and demand components are compared to the sign of the TCF indicator, policymakers might be able to understand whether output growth is explained by supply, demand or both shocks, for instance.

Providing that both supply and demand shocks can have immediate (short-run) impact on output, the question of whether these shocks can cause unbalances that lead to strong adjustments in prices ensues. We define a goods market unbalance (GMU indicator) as the difference or wedge between the demand and supply components of output. Significantly large (positive) or small (negative) values of this indicator point out that supply and demand shocks have important reinforcing effects on prices that increase or reduce inflation meaningfully, but opposite effects on output. Likewise, a substantial output wedge suggests that households' and firms' decisions are potentially inconsistent. ${ }^{5}$ It is precisely when these unbalances take place that policy interventions are fully justified. ${ }^{6}$ Although it is beyond the scope of this paper to elucidate the determinants of goods market unbalances, its calculation for our sample of countries suggests the emergence of common patterns in the region around 2008-2009 and 2013-2014.

The structure of the paper is the following: in the next section we argue why supply shocks can have immediate impacts in the goods market from the perspective of New Keynesian DSGE models and rationalize our general identification strategy. Then, in the third section, we present the details of the core methodological proposal and discuss it in contraposition to the Blanchard-Quah methodology. In this section, we also formally define the two indicators suggested for policy analysis: the TCF and GMU indicators. In the fourth section, we apply the methodology proposed for each of the countries mentioned, show the use of the indicators for policy analysis and evaluate the impact of demand and supply shocks through variance decompositions. In the fifth section, we compare our calculations with the Hodrick-Prescott output gap and with historical decompositions obtained according to two additional procedures: the implementation of long-run restrictions on a SVAR in output growth and unemployment (the original Blanchard-Quah setup), and the application of long-run restrictions on a SVAR in output growth and inflation.

\footnotetext{
${ }^{5}$ For instance, simultaneous positive demand and negative supply shocks have positive impact on inflation because firms are reducing their supply of goods while households are increasing their demand. The prevailing effect on output will depend on the magnitude of shocks.

${ }^{6}$ A more theoretical justification for this indicator is available in the next section. A policy oriented interpretation for both indicators is provided in section 4 .
} 
This exercise allows us to investigate whether the use of prices or long-run restrictions is more important for an adequate identification of structural disturbances. The sixth section presents a summary of the findings.

\section{Why supply shocks can have a short-run impact on output}

One important problem with the afore-mentioned practitioners' wisdom is that it seems to neglect or fails to incorporate some of the implications of modern New Keynesian DSGE models. As pointed out by Basu and Fernald (2009), New Keynesian models provide a way to think formally about the all sources of business cycle fluctuations (nominal and real shocks) while integrating the long-run vision of one-sector neoclassical growth models with the notion of short-run fluctuations of early Keynesian models. However, New Keynesian models do not imply either that potential output is a smooth trend or that the short-run variance of output does exclusively depends on nominal (demand) shocks. As these authors explain, the formal definition of potential output within these models refers to the "rate of output the economy would have if there were no nominal rigidities but all the other (real) frictions and shocks remained unchanged". Therefore, if for instance, technology shocks exhibit a high volatility, potential output is also rather volatile. ${ }^{7}$ Regarding this matter, they argue there is scant empirical evidence supporting the belief that technology changes smoothly over time. In relation to output variability, they state that empirical evidence suggests that a substantial fraction of the variance of total factor productivity (TFP) and GDP is explained by innovations to technology. Our interpretation of this last piece of evidence is that this same variability of the TFP can explain adjustments in firms' marginal costs that lead to change their production in the short-run. In particular, increasing TFP allows firms to produce more at lower prices, a notion associated with output supply.

Besides the disputable source of technology shocks, another feature of most New Keynesian DSGE models is that labor supply can greatly respond to changes in household wealth. This implies that any shock affecting wealth, such as fiscal or real exchange shocks, might change labor supply and therefore, explain part of the volatility of output (with and without nominal rigidities) in the short-run. In other words, the elasticity of labor supply can modify wages, and consequently the marginal costs faced by firms, prior to any adjustment in inputs' demand and utilization. Moreover, these adjustments in labor supply can describe a negative correlation between salaries and hours worked in equilibrium, a relationship clearly related to supply shocks.

Recent literature concerning the role of imported intermediate goods on productivity, Gopinath and Neiman (2014) and Halpern, Koren, and Szeidl (2015) have shown that a sizable share of the productivity of open economies, such as the Argentinian and the Hungarian, can be associated with changes in the price and quantities (of varieties) of imported intermediate goods. That is,

\footnotetext{
7 See Basu and Fernald (2009) for a more detailed discussion about the definition and estimation of potential output.
} 
cheaper imports allow some firms to import a greater variety of intermediate goods and increase their supply for the rest of firms. Because importers usually exert some market power, a greater provision of intermediate goods implies efficiency gains and reduction of costs for these firms. Given the roundabout nature of production and some degree of imperfect competition also in the provision of final goods, aggregate TFP and output increase. This happens independently of the gains in output that could take place because of the presence of increasing returns to scale, as suggested in Basu (1995) for closed economies, and in Gopinath and Neiman (2014) for open economies.

Another type of result that can be obtained within standard New Keynesian models is the one pointed out by Fernández-Villaverde, Guerrón-Quintana, Kuester, and Rubio-Ramírez (2015). In their model, a greater uncertainty (volatility) about fiscal policy (tax and spending processes) translates into a reduction in output and a rise in firms' markup that increases inflation. The rise in firms' markup is a response to the greater uncertainty regarding future marginal costs. For such fiscal shock, the economy ends up producing less output at higher prices.

Overall, all the above theoretical mechanisms intend to show that variations in the prices of production's factors, modifications in TFP (due to technological or non-technological shocks) and markup changes can all lead to adjustments in firms' production (output-price) decisions. Moreover, these firms' supply responses are not triggered by any perturbation in the demand of their products. In other words, due to the existence of real frictions (imperfect competition), the supply of goods by firms is explained by modifications in the environment that are not necessarily demand-driven.

Theoretically, supply shocks are commonly related to upward or downward shifts in firms' marginal cost schedules, while demand shocks are associated with changes in households' decisions that affect the goods' demand faced by firms. But, as already explained, the exercise of market power by firms opens up the possibility that firms can also adjust the prices of their final goods, even if actual marginal costs have not been altered. As a consequence, the definition of supply shocks calls for a more ample notion than shifts in marginal costs. ${ }^{8}$ As already suggested in some works of the empirical literature, a more general definition of supply shocks should simply relate to the observational event that quantities and prices in the goods market adjust in opposite directions. We precisely adopt this notion because, under this view, all possible sources of adjustments in firms' decisions are taking into consideration. By analogy, demand shocks can then be defined as all perturbations occurring in the economy that lead to adjustments in quantities and prices in the goods market in the same direction.

A consequence of acknowledging that supply shocks can affect output in the short-run is that the notion of output gap, commonly implemented as the

\footnotetext{
8 It is also the case, that firms exercising market power in input markets can affect the prices of these inputs. Nonetheless, these changes in input prices should be reflected in changes in marginal costs.
} 
difference between actual output and its trend, becomes problematic. In the first place, it raises a measurement problem. While output gap estimates might actually contain information about both demand and supply shocks, they are interpreted as if they were strictly driven by aggregate demand shocks. The second-related problem is that the interpretation of events offered by output gaps constitutes an inappropriate representation of reality that might lead to incorrect policy diagnosis and decisions. When interpreting the output gap, because of its clear procyclicality, all output fluctuations are subject to monetary policy interventions: all fluctuations are demand-driven.

Then, what would it be the counterpart of a gap in the goods market, while acknowledging the effects of both supply and demand shocks in the short-run? Because a statistical model that disentangles supply from demand shocks cannot address the theoretical notion of potential output, which is clearly related to the existence of full flexible prices, we resort to the notion of an unbalance in the goods market. This unbalance can be understood as all possible situations where supply and demand shocks cause inconsistent reactions between firms and households that lead to reinforcing effects on inflation. For instance, if our statistical model indicates the simultaneous occurrence of expansionary demand and contractionary supply shocks, while households increase their demand of goods, firms reduce their supply. In this case, the economy will be experiencing important inflationary pressures, but the behavior of output is a priori undetermined: it will depend on the magnitude of shocks. This inconsistency in agents' responses to disturbances could also lead to unsustainable macro-dynamics (stagflation for instance), and to further economic unbalances with potential aggregate welfare losses. ${ }^{9}$ The operational definition of unbalance in the goods market (GMU) is simply the difference or wedge between the demand and the supply components of output.

For policy analysis purposes, the detection of significant unbalances might also lead to policy interventions, but not necessarily to monetary interventions. This is because determining the type of policy intervention requires a diagnosis about which shock is generating the unbalance. For instance, unbalances clearly driven by contractionary supply shocks might preclude the response of monetary authorities. Examples on how to use this GMU indicator for policy evaluation are illustrated in section 4 .

\section{Core methodological proposal}

When economists address the sources of short-run fluctuations, we may think of a broad category of disturbances, ranging from policy shocks that typically affect aggregate demand to labor market and productivity shocks. In this case, the empirical identification strategy of shocks depends on the particular

\footnotetext{
9 For example, one could speculate that simultaneously having firms reducing their supply of goods and households increasing their demand might translate into a bust in real activity and a sizable demand for banking credit. This intuitively could depict the conditions for the future emergence of financial distress with the associated welfare loss.
} 
interest of the researcher and on the problems that arise when omitting relevant information. Nonetheless, to gain a more general view of what is driving the economic performance at a precise point in time, we can resort to classifying all the above primitive shocks according to their impact on the goods market, that is, simply as supply or demand shocks. As already mentioned, supply (demand) shocks are defined as all perturbations occurring in the economy that lead to observable adjustments in quantities and prices of the goods market in the opposite (same) direction.

We start with a reduced VAR in output growth and inflation in order to identify supply and demand shocks. We restrict the VAR specification to only these two variables because first, we do not need more information for correctly identifying supply and demand shocks, and second, we want these shocks to explain all the variability of output growth and inflation. ${ }^{10}$ As a consequence, identified shocks can be interpreted as a cluster or summary of diverse more primitive types of shocks whose net effects have the imposed features on the data.

We proceed to the identification of shocks using sign restrictions because this methodology allows us to impose the expected co-movements in prices and quantities in response to a shock. That is, shocks identified with sign restrictions can address (positive or negative) contemporaneous correlations among a several variables in a system without imposing zero restrictions on the effects of shocks. ${ }^{11}$ Canova (2005) already applies sign restrictions to identify supply and demand shocks according to their effects on output and prices in systems of more than two variables. ${ }^{12}$ However, in these exercises, identification was implemented to analyze transmission mechanisms of shocks. The use of this identification strategy for monitoring cyclical fluctuations and improving policy discussions, as we suggest in this article, has not been exploited.

Because our statistical framework could be considered a variant of the Blanchard and Quah (1989) methodology, we discuss the main differences. The Blanchard-Quah methodology imposes that only supply shocks can have permanent effects on output, while demand shocks are necessarily long-run neutral for output. In the short-run however, either supply or demand shocks can have effects on output. Under these premises, the adequacy of their identification relies on the validity of the temporariness of shocks' effects in the long-run. We believe that establishing the direction of shocks' impacts on

\footnotetext{
${ }^{10}$ Although one might argue that output and prices are determined by many other variables not included in the VAR, this endogeneity does not constitute a problem if we are not interested in tracking down and explaining transmission mechanisms. Instead, we are just focusing on characterizing the full observed behavior of prices and output, only conditional on the existence of supply and demand shocks.

11 This identification technology is proposed separately by Canova and Nicoló (2002) and Uhlig (2005). It has been used in the literature to identify monetary policy shocks, technology shocks, and also to distinguish the effects of demand and supply shocks on certain variables.

12 Other examples of the international literature using prices for identifying supply and demand shocks are: in a SVAR context, Eickmeier, Hofmann, and Worms (2009); in FVAR setups, Mumtaz and Surico (2009), Eickmeier and Hofmann (2013) and Buch, Eickmeier, and Prieto (2014).
} 
output and prices in the short-run is sufficient for achieving a successful identification, because of the theoretical reasons previously addressed. But empirically, imposing short-run restrictions is more general or encompassing than using long-run restrictions. This is the case because short-run restrictions do not rule out the possibility that any shock could have a permanent effect either on output or prices. ${ }^{13}$ Another important difference with Blanchard and Quah (1989) is that these authors use output growth and unemployment for VAR estimation and identification. At this point, any differences obtained between the application of our proposal and the Blanchard-Quah methodology could be attributed either to the information contained in the VAR or to the type of identification employed. This is an issue that will be explored in section 5 .

The identification of structural aggregate supply and demand shocks using short-run restrictions is carried out as follows. Consider $\mathrm{Z}$ the vector of endogenous variables $(y, p i)$ ' that represents the annualized growth rate of the indexes of economic activity and prices respectively, and $\varepsilon$ de vector of structural shocks $\left(\varepsilon^{S}, \varepsilon^{D}\right)$ '. The reduced VAR is given by:

$Z_{t}=\mathrm{A} Z_{t-1}+e_{t}$

where $\mathrm{A}$ is the companion matrix of auto-regressive coefficients, and $e=\left(e^{y}, e^{p i}\right)$ is the vector of the reduced-form residuals with covariance matrix $\Sigma$.

Impulse-responses of structural shocks are computed from the expression:

$$
I R_{t}=\mathrm{A}^{t-1} P Q
$$

where $P$ is an arbitrary orthogonalization of the covariance matrix of reduced residuals that satisfies $\Sigma=P P^{\prime}$, and $Q$ is a rotation matrix that satisfies $Q Q^{\prime}=Q^{\prime} Q=I{ }^{14}$ Operationally, using sign restrictions entails to find enough rotations matrices $Q s$ that satisfy the restrictions imposed on IRs. Because there are always several rotation matrices that satisfy the restrictions imposed, the model is over-identified. ${ }^{15}$ All these Q matrices also convey the uncertainty on structural parameters that stems from this identification technique.

Since expression (2) provides a lineal relationship between reduced-form and structural disturbances, structural shocks can be recovered through the

\footnotetext{
13 As pointed out in Fisher, Huh, and Pagan (2015), sign restrictions do not distinguish between demand shocks with permanent and non-permanent effects. However, this is not a problem because our objective is to implement a notionally more general identification strategy.

14 This orthogonalization can be achieved by a Cholesky decomposition or by a spectral decomposition (using eigenvectors and eigenvalues). Results tend to be robust to the selection of the orthogonalization method. Rotation matrices are obtained by applying the QR decomposition to a unitary random matrix.

${ }^{15}$ See Rubio-Ramírez, Waggoner, and Zha (2010) for a detailed theoretical discussion about model identification using sign restrictions and the algorithm for identification.
} 
expression: $e_{t}=P Q \varepsilon_{t}$. Because we can obtain as many structural residual series as the number of rotation matrices kept, we can proceed in two ways in order to reduce this parametric uncertainty. One procedure is to compute the median trajectory of structural shocks out of all possible series. Another way is to construct a unique sequence of structural residuals based on the selection of a particular matrix $Q^{*}$. As Fry and Pagan (2011) suggest, we could pick the matrix $Q^{*}$ that minimizes the distance to the median trajectory of structural shocks. But because structural shocks can be very sensitive to the selection of the rotation matrix $Q^{*}$, we suggest using their median trajectory to obtain a more robust description of their historical behavior. What this treatment of the parametric uncertainty looks for is to equate sign restriction identification to the other forms of identifications available in the literature. In fact, uncertainty regarding structural parameters also exists when estimating reduced VARs with OLS, but it is not usually acknowledged because of the deterministic identification technique employed for identification (Cholesky decomposition for instance). Later in the paper we will show for example, that some of the results obtained through our methodology are highly correlated with some of the results obtained from the Blanchard-Quah identification. This is an indication that disregarding parametric uncertainty does not necessarily constitute a problem, or at least that the results obtained with this procedure are not essentially different (statistically speaking) from the results obtained with other procedures available in the literature.

Identification of structural shocks is achieved by imposing the following conditions on structural impulse-responses:

Table1. Conditions imposed on impulse-responses for structural shocks

\begin{tabular}{|c|c|c|}
\hline & $\begin{array}{c}\text { Expansionary Aggregate } \\
\text { Supply Shock }\end{array}$ & $\begin{array}{c}\text { Expansionary Aggregate } \\
\text { Demand Shock }\end{array}$ \\
\hline$y$ & + & + \\
\hline$p i$ & - & + \\
\hline
\end{tabular}

These restrictions are applied for several consecutive periods to capture shocks whose effects on variables are sufficiently large or long-lasting. ${ }^{16}$

From impulse-responses, we can observe, for instance, how quickly shocks' effects die out. Also, we can compute variance decompositions to gauge which type of shock dominates the variability of output growth and inflation at different horizons. However, in order to understand, at a particular point in time, the impact of a shock on a variable, we need to compute historical decompositions. Historical decompositions are calculated for each type of shock along $\tau$ periods as follows:

\footnotetext{
16 The length of time for applying sign restrictions can vary depending on the existence of $a$ priori assumption regarding the definition of shocks.
} 


$$
\begin{aligned}
& H D Z_{t}^{S}\left(\varepsilon^{S}, \tau\right)=Z_{t}\left(\varepsilon^{S}\right)-\mathrm{A}^{\tau} Z_{t-\tau-1}=\sum_{j=0}^{\tau-1} \mathrm{~A}^{j} P q^{S} \varepsilon_{t-j}^{S} \\
& \operatorname{HDZ}_{t}^{D}\left(\varepsilon^{D}, \tau\right)=Z_{t}\left(\varepsilon^{D}\right)-\mathrm{A}^{\tau} Z_{t-\tau-1}=\sum_{j=0}^{\tau-1} \mathrm{~A}^{j} P q^{D} \varepsilon_{t-j}^{D}
\end{aligned}
$$

where $Z_{t}(\varepsilon)$ denotes the forecasted value of $Z$ at time $t$, given the information of $\tau$ shocks $\left(\varepsilon_{t}, \varepsilon_{t-1}, \ldots, \varepsilon_{t-\tau+1}\right)$, and $q$ denotes the column of matrix $Q$ associated with the specific analyzed shock. In this case, a particular Q must be necessarily selected in order to ensure the orthogonality between the columns vectors of the rotation matrix used. This time, we do follow Fry and Pagan (2011) for choosing the particular matrix Q, that is, we pick the rotation matrix that delivers structural residuals closer to their median value. This procedure is carried out by computing the sum of squared differences between each structural shock series and their respective median value.

As the formulae indicate, historical decompositions capture the accumulated effects of a structural shock on variables during $\tau$ periods. The first element of $\operatorname{HDZ}_{t}^{S}\left(\varepsilon^{s}, \tau\right)$ is the cyclical component of output growth due to supply shocks $y_{t}^{S}(\tau)$, while the first element of $\operatorname{HDZ}_{t}^{D}\left(\varepsilon^{D}, \tau\right)$ is the cyclical component of output growth due to demand shocks $y_{t}^{D}(\tau)$. Because structural shocks have different magnitudes and timing, historical decompositions offer a narrative of what is happening to the economy at each point in time.

Because components are equivalent to the portion of the actual variable that is explained by a shock, the sum of the supply and demand components of output growth provides a natural indicator for total cyclical fluctuations (TCF):

$\operatorname{TCF}_{t}(\tau)=y_{t}^{S}(\tau)+y_{t}^{D}(\tau)$

A positive (negative) sign of this indicator points out whether the actual variable is growing (falling) above (below) its long-run or steady state value. That is, the sign of TCF provides the net effect of shocks on output in relation to its long-run rate. This is so, because the difference between the actual variables and the sum of their components, i.e. $Z_{t}-H D Z_{t}^{S}-H D Z_{t}^{D}$, delivers a value comparable to their steady state value. This interpretation is consistent with the notion that, in the absence of shocks, variables tend to converge to a constant value. ${ }^{17}$

Comparing $y_{t}^{S}$ and $y_{t}^{D}$ with the sign of $T C F_{t}$ allows policymakers to understand if supply or demand shocks dominate output growth or if both shocks contribute to its behavior. Likewise, comparing the second elements of historical decompositions, i.e. $p i_{t}^{S}$ and $p i_{t}^{D}$, with the sign of their sum shows whether inflation is actually increasing or decreasing in response to such shocks.

\footnotetext{
${ }^{17}$ This is true, as long as $\tau$ is sufficiently long to capture the complete dynamic of short term shocks.
} 
The second indicator captures the unbalance in the goods market (GMU), which is defined as the difference between the supply and the demand components of output growth:

$$
\operatorname{GMU}_{t}(\tau)=y_{t}^{D}(\tau)-y_{t}^{S}(\tau)
$$

If this indicator takes persistently large (positive) or small (negative) values, it suggests that the economy is entering in a dynamic path of inflation or deflation that could be undesirable. When the GMU is compared with the sign of the TCF of output, we can have more precise information on whether monetary policy interventions are desirable. This is because we need to know which side of the market is short and what the net effect of shocks is. How to jointly interpret the information provided by these two indicators is addressed in the next section.

\section{Cyclical fluctuations in countries and policy analysis}

In this section, we apply the methodology proposed to the data collected for Argentina, Brazil, Chile Colombia, Mexico, Peru, United States and Venezuela.

The selection of the starting point of the sample period is different for each country and depends on data availability and the stability of parameter estimates. Samples chosen are: Argentina (1999-2012), Brazil (1996-2012), Chile (1997-2012), Colombia (1999-2012), Mexico (1998-2012), Peru (20002012), United States (1999-2012) and Venezuela (1999-2012). In the estimation of the reduced-form VAR, issues such as the selection of optimal lags, stability and autocorrelation of residuals were addressed using standards statistical tests. In the selection of the lag length, since tests might provide different suggested lags, we balanced the parsimony of the model versus the excessive presence of autocorrelation. All countries models use 3 or 4 lags. Orthogonalization of reduced-form residuals is obtained using Cholesky decomposition. Historical decompositions are computed for $\tau$ equal to either 24 or 36 periods, depending on how quickly impulse-responses die out. Measurement of the unbalance in the goods market (GMU) and total cyclical fluctuations (TCF) is also carried out for each country. These results are summarized in figures 1 and 2 . Table 2 presents the variance decomposition of shocks for both output growth and inflation. 
Figure 1. Historical decomposition of output growth

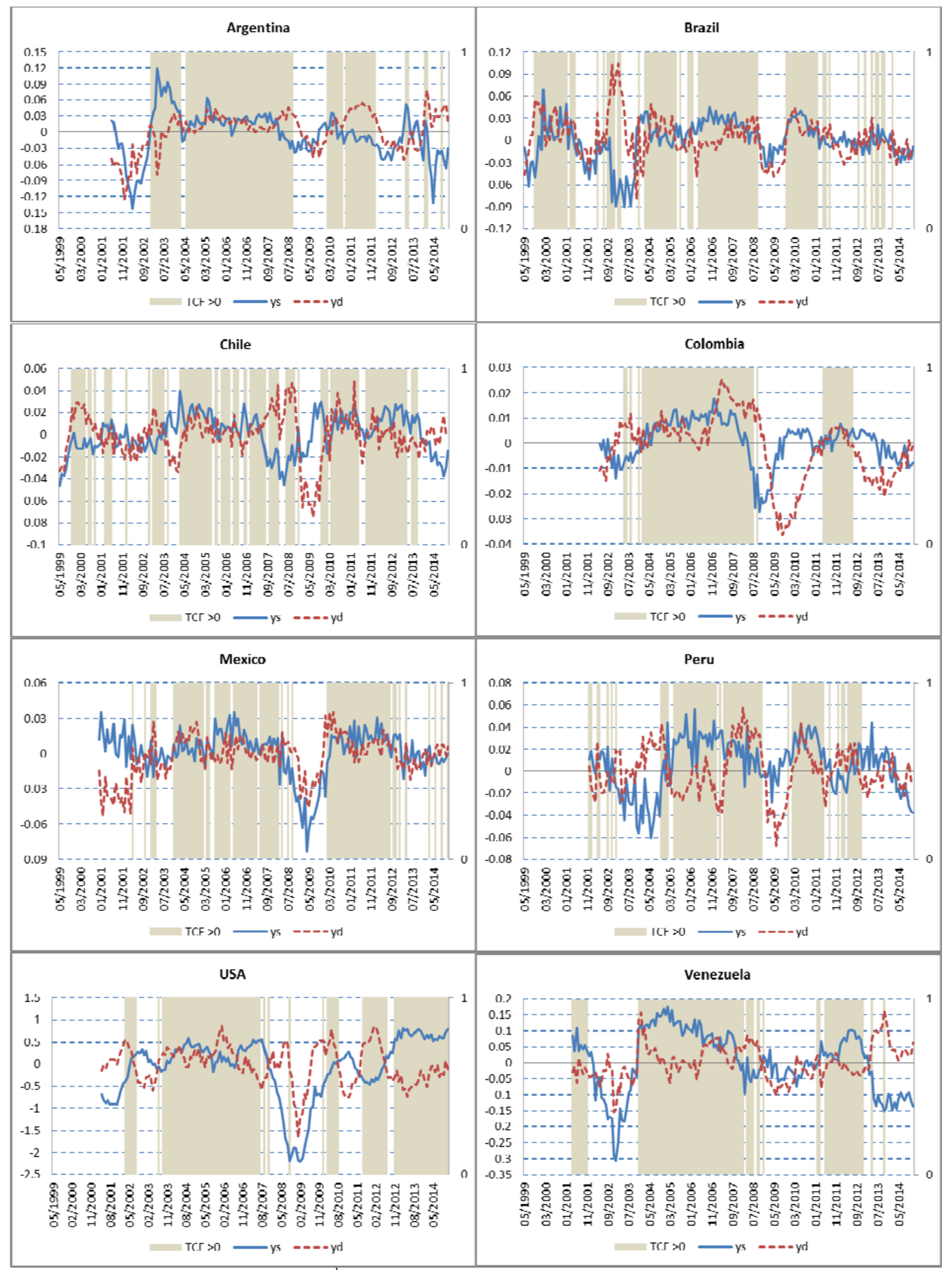

$y^{\text {s: }}$ supply component of output growth; $y^{d}$ : demand component of output growth. 
Figure 2. Unbalance in the goods market

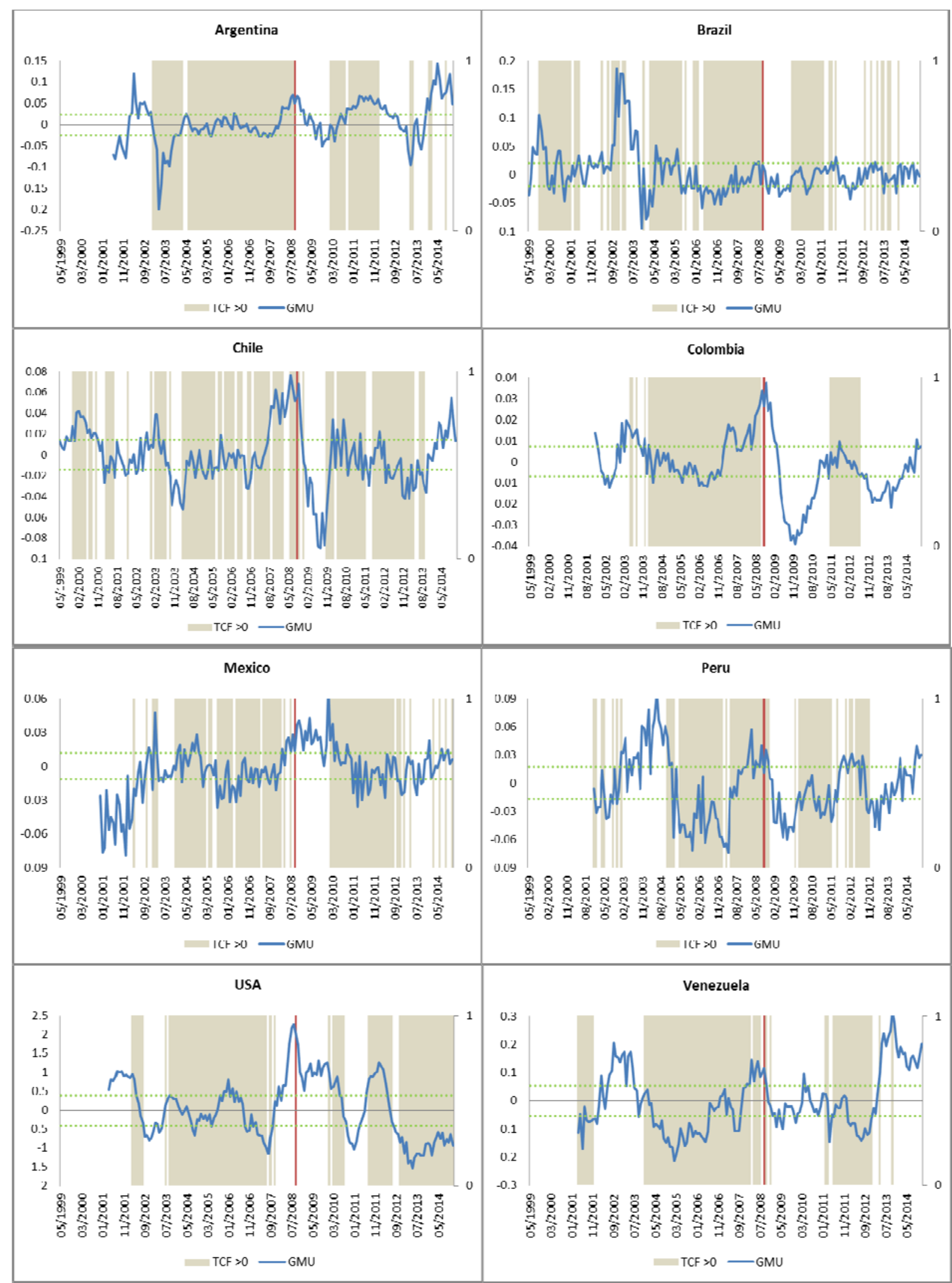

TCF: total cyclical fluctuations of output growth; GMU: goods market unbalance. 
Generally speaking, in figure 1, fluctuations of the supply and demand output components widely vary across countries in terms of their level, volatility and duration, denoting important statistical differences in the properties of the original variables and the impact of shocks. For instance, Argentina, Colombia, Peru and Venezuela show longer and more defined cycles in their output components than Brazil, Chile, Mexico and the United States.

However, the most important information contained in figure 1 refers to the interaction between supply and demand components at each point in time. For instance, there are episodes of output growth above its long-run mean $(\mathrm{TCF}>0)$ clearly driven by aggregate demand shocks, as it is the case for Argentina in 2011 or Colombia in 2007. But there are many other episodes where growth is largely explained by aggregate supply shocks, as the cases of Peru in 2005-2006, Venezuela in 2005-2006 or the United States in 20132014. On the other hand, there are recessions $(\mathrm{TCF}<0)$ in which contractionary demand shocks are dominating the output dynamic (Peru or Chile during 2009). We can find cases as well where the decline in output can be attributed to contractionary supply shocks (Argentina, Chile or Venezuela in 2014). Other episodes illustrate that supply and demand components tend to move along, indicating that both shocks contribute to the output performance, such as Argentina in 2005-2007, Chile in 2004-2006 or Mexico in 2007. Overall, these examples show that the expansion or contraction of the economy can depend on either type of shock, and that demand shocks do not always characterize the short-run behavior of output.

Besides this relevant information, policy analysis focuses on situations where interventions are justified. This information is more connected to the behavior of the GMU indicator (the "more agnostic" counterpart of the output gap). Because only episodes of important unbalances (GMU $\neq 0)$ are interesting for policy intervention, we need to classify unbalances accordingly. ${ }^{18}$ So, in figure 2 , we point out to the episodes of significant unbalances by discretionally drawing two lines corresponding to the positive and negative half standard deviation of the GMU indicator.

Based on the combination of the information provided by the TCF and GMU indicators, we can characterize policy interventions as follows:

- For TFC $>0$ and GMU $>0$ : output growth is sustained by expansionary demand shocks and potential risks are on the side of rising inflation (economic overheat). Contractionary monetary policy is advisable, especially if the unbalance occurs because fiscal or monetary policies are being too expansionary. However, if there are other (domestic or external) events increasing aggregate demand while also reducing aggregate supply, then the implementation of contractionary monetary policy should be carefully evaluated.

- For $\mathrm{TCF}<0$ and GMU $>0$ : output drop is dominated by contractionary supply shocks that also raise inflation. In this case, the roots of the problem

\footnotetext{
${ }^{18}$ In situations of non-significant unbalances (GMU close to zero), supply and demand shocks tend to have positive effects on output growth $(\mathrm{TCF}>0)$, while inflation remains stable.
} 
are probably outside the realm of monetary policy. Contractionary monetary policy can be counterproductive for output growth without solving the causes of rising inflation. Policy interventions (different than monetary policy) should carefully evaluate the causes driving supply shocks.

- For $\mathrm{TCF}>0$ and $\mathrm{GMU}<0$ : output growth is sustained by expansionary supply shocks. Risks are on the side of deflation in economies that are already at low levels of inflation. There is room for expansionary monetary policy unless the economy is moving to a lower inflation objective.

- For $\mathrm{TCF}<0$ and $\mathrm{GMU}<0$ : output drop is dominated by contractionary demand shocks that also reduce inflation. This could mean that fiscal or monetary policies are being too contractionary (procyclical), or that other (domestic or external) events are reducing aggregate demand. Expansionary monetary policy is advisable, at least to the point of reducing the wedge between the supply and the demand components.

In figure 2, a careful revision of the different countries' experiences shows that, even though there are important differences in the behavior of the GMU indicators, some patterns arise. For example, during the period 2005-2006 Peru, Venezuela, and in lesser extent Brazil, Colombia, and Mexico, exhibit real growth above their long-run mean $(\mathrm{TCF}>0)$, while experiencing positive supply and negative demand shocks $(\mathrm{GMU}<0)$. That is, for that period, growth is driven by expansionary supply shocks, while inflation is falling. Another emerging pattern is that, somewhere during 2007 and part of 2008, all Latin American countries (except Brazil) start showing a clear significant positive unbalance $(\mathrm{GMU}>0)$ and rising inflation with positive output growth $(\mathrm{TCF}>0)$. This means that in spite of the occurrence of contractionary supply shocks, aggregate demand pressures sustain growth. For this same period, in the United States, the unbalance is also positive, but output falls below its longrun mean $(\mathrm{TCF}<0)$. In this case, contractionary supply shocks are very large and drive output performance, while increasing inflation. A superficial reading of these two indicators would suggest that the solution of real slowdown in the United States was probably outside the realm of monetary policy decisions. ${ }^{19}$ Then, after September 2008, which is marked with a red line, the unravelling of the United States' financial crisis seems to start dissipating those positive unbalances in the region, especially in Latin America. During 2013-2014, Argentina, Chile and Venezuela show again positive unbalances in the goods market (GMU $>0$ ), while Colombia and Peru could be facing their beginning. This time, differently than in 2008, these countries seem to experience a dropping output $(\mathrm{TCF}<0)$ due to the clear effects of contractionary supply shocks. As already suggested, for these cases contractionary monetary policy could be counterproductive, even though inflation is rising.

It is beyond the scope of this paper to analyze the conditions that determine the appearance of these unbalances, since for this purpose we would need to

19 This does not mean that monetary policy could have been countercyclical (expansionary), as it actually was. It only means that in cases like this, monetary policy responses are not likely to change the reduction in firms' supply, unless it is believed that former contractionary monetary policy actions were the actual trigger for firms' behavior in the first place. 
analyze a greater set of macroeconomic variables. However, it should stand for itself that analyzing historical decompositions in the way proposed gives the possibility for discussing policy questions of utmost interest. ${ }^{20}$

Looking at the variance decompositions (table 2), we can have a more definite assessment of the average explanation power of shocks for output growth and inflation. But first, we determine their prevalence for the first and last period of impulse-responses. In the long term (24 or 36 months), most of the output fluctuations are greatly explained by supply shocks. This also means that in general, the effects of supply shocks on output tend to be more persistent than the effects of demand shocks. This is true for most countries, except for Argentina, Brazil and to less extent, for Colombia. In the very short-run, supply shocks also have their major effect on output for Argentina and Peru, but share their importance with demand shocks for Colombia, Mexico and Venezuela. Overall, in 5 out of 8 countries, supply shocks explain more than $50 \%$ of the output variance in the short-run. In the remaining countries (Brazil, Chile, and United States), for the very short-run, demand shocks seem to prevail over supply shocks. Because for the United States, the effects of these demand shocks die out soon, we can state that largely, the results of Blanchard and Quah (1989) still hold for this estimation period.

When looking at inflation, in the long-run, most of the inflation fluctuations are greatly explained by demand shocks. This is true for all countries, except for Argentina and Venezuela. Contrary, in the very short-run, supply shocks explain major changes in inflation for Brazil, Mexico, and the United States, and share their importance with demand shocks for Chile and Venezuela. Therefore, the relevance of supply shocks for explaining short-run inflation does not seem to be of second order or simply related to isolated events such as natural extreme conditions.

\footnotetext{
20 Another relevant piece of information for policy analysis refers to the historical decomposition of inflation. Because demand and supply shocks do not impact output and inflation with the same intensity, looking at inflation components can provide a more precise idea on the effects of shocks. However, the information provided by joint analysis of the TCF and the GMU indicators is qualitatively similar.
} 
Table 2. Accumulated variance decomposition of shocks

\begin{tabular}{|c|c|c|c|c|c|c|c|}
\hline \multirow[b]{2}{*}{ Country } & \multirow[b]{2}{*}{ Month } & \multicolumn{3}{|c|}{ Output growth } & \multicolumn{3}{|c|}{ Inflation } \\
\hline & & $\begin{array}{c}\text { Supply } \\
\text { shock }\end{array}$ & $\begin{array}{c}\text { Demand } \\
\text { shock }\end{array}$ & $\begin{array}{c}\text { Prevalence* at } \\
\text { 1st and 24th or } \\
\text { 36th }\end{array}$ & $\begin{array}{c}\text { Supply } \\
\text { shock }\end{array}$ & $\begin{array}{l}\text { Demand } \\
\text { shock }\end{array}$ & $\begin{array}{c}\text { Prevalence* at } \\
\text { 1st and 24th or } \\
\text { 36th } \\
\end{array}$ \\
\hline Argentina & $\begin{array}{c}1 \\
12 \\
24 \\
\end{array}$ & $\begin{array}{l}62 \% \\
53 \% \\
19 \% \\
\end{array}$ & $\begin{array}{l}38 \% \\
47 \% \\
81 \% \\
\end{array}$ & $\begin{array}{l}\text { Supply } \\
\text { Demand }\end{array}$ & $\begin{array}{l}45 \% \\
66 \% \\
69 \% \\
\end{array}$ & $\begin{array}{l}55 \% \\
34 \% \\
31 \% \\
\end{array}$ & $\begin{array}{l}\text { Demand } \\
\text { Supply }\end{array}$ \\
\hline Brazil & $\begin{array}{c}1 \\
12 \\
24 \\
\end{array}$ & $\begin{array}{l}39 \% \\
45 \% \\
43 \% \\
\end{array}$ & $\begin{array}{l}61 \% \\
55 \% \\
57 \% \\
\end{array}$ & $\begin{array}{l}\text { Demand } \\
\text { Demand }\end{array}$ & $\begin{array}{l}59 \% \\
49 \% \\
45 \% \\
\end{array}$ & $\begin{array}{l}41 \% \\
51 \% \\
55 \% \\
\end{array}$ & $\begin{array}{l}\text { Supply } \\
\text { Demand }\end{array}$ \\
\hline Chile & $\begin{array}{c}1 \\
12 \\
24 \\
\end{array}$ & $\begin{array}{l}35 \% \\
55 \% \\
91 \% \\
\end{array}$ & $\begin{array}{c}65 \% \\
45 \% \\
9 \% \\
\end{array}$ & $\begin{array}{l}\text { Demand } \\
\text { Supply }\end{array}$ & $\begin{array}{l}54 \% \\
29 \% \\
26 \% \\
\end{array}$ & $\begin{array}{l}46 \% \\
71 \% \\
74 \% \\
\end{array}$ & $\begin{array}{c}\text { None } \\
\text { Demand }\end{array}$ \\
\hline Colombia & $\begin{array}{c}1 \\
12 \\
24 \\
36\end{array}$ & $\begin{array}{l}54 \% \\
35 \% \\
39 \% \\
47 \% \\
\end{array}$ & $\begin{array}{l}46 \% \\
65 \% \\
61 \% \\
53 \% \\
\end{array}$ & $\begin{array}{l}\text { None } \\
\text { None }\end{array}$ & $\begin{array}{l}44 \% \\
32 \% \\
33 \% \\
34 \% \\
\end{array}$ & $\begin{array}{l}56 \% \\
68 \% \\
67 \% \\
66 \% \\
\end{array}$ & $\begin{array}{l}\text { Demand } \\
\text { Demand }\end{array}$ \\
\hline Mexico & $\begin{array}{c}1 \\
12 \\
24 \\
36\end{array}$ & $\begin{array}{l}52 \% \\
60 \% \\
63 \% \\
66 \%\end{array}$ & $\begin{array}{l}48 \% \\
40 \% \\
37 \% \\
34 \%\end{array}$ & $\begin{array}{l}\text { None } \\
\text { Supply }\end{array}$ & $\begin{array}{l}59 \% \\
48 \% \\
34 \% \\
26 \%\end{array}$ & $\begin{array}{l}41 \% \\
52 \% \\
66 \% \\
74 \%\end{array}$ & $\begin{array}{l}\text { Supply } \\
\text { Demand }\end{array}$ \\
\hline Peru & $\begin{array}{c}1 \\
12 \\
24 \\
\end{array}$ & $\begin{array}{l}57 \% \\
80 \% \\
99 \% \\
\end{array}$ & $\begin{array}{c}43 \% \\
20 \% \\
1 \% \\
\end{array}$ & $\begin{array}{l}\text { Supply } \\
\text { Supply }\end{array}$ & $\begin{array}{c}45 \% \\
14 \% \\
0 \% \\
\end{array}$ & $\begin{array}{c}55 \% \\
86 \% \\
100 \% \\
\end{array}$ & $\begin{array}{l}\text { Demand } \\
\text { Demand }\end{array}$ \\
\hline USA & $\begin{array}{c}1 \\
12 \\
24 \\
\end{array}$ & $\begin{array}{l}29 \% \\
79 \% \\
98 \% \\
\end{array}$ & $\begin{array}{c}71 \% \\
21 \% \\
2 \% \\
\end{array}$ & $\begin{array}{c}\text { Demand } \\
\text { Supply }\end{array}$ & $\begin{array}{c}79 \% \\
34 \% \\
2 \% \\
\end{array}$ & $\begin{array}{l}21 \% \\
66 \% \\
98 \% \\
\end{array}$ & $\begin{array}{l}\text { Supply } \\
\text { Demand }\end{array}$ \\
\hline Venezuela & $\begin{array}{c}1 \\
12 \\
24\end{array}$ & $\begin{array}{l}54 \% \\
74 \% \\
84 \%\end{array}$ & $\begin{array}{l}46 \% \\
26 \% \\
16 \%\end{array}$ & $\begin{array}{l}\text { None } \\
\text { Supply }\end{array}$ & $\begin{array}{l}52 \% \\
72 \% \\
71 \%\end{array}$ & $\begin{array}{l}48 \% \\
28 \% \\
29 \%\end{array}$ & $\begin{array}{l}\text { None } \\
\text { Supply }\end{array}$ \\
\hline
\end{tabular}

*One type of shock prevails over the other if explains a $10 \%$ more of variance of the variable.

\section{Comparisons with related measures}

One issue briefly discussed in section 2 is that output gap estimates, especially when obtained from the application of univariate mechanical filters, tend to contain information on both, supply and demand shocks, but they are typically interpreted as being only demand driven. In this section we compare HodrickPrescott (HP) output gap estimates with the supply and demand components of output and with the TCF indicator already presented.

HP output gap estimates can be calculated in two ways: the conventional one, using the log of the seasonally adjusted level of the activity indicator, and the second one, applying the filter directly to the growth rate of activity. We use output gap estimates computed from growth rates because the VAR analysis 
and historical decomposition refers to growth rates. ${ }^{21}$ In tables 3, we show pairwise correlations between the output gap estimates (from the growth rate) and each of output growth components: supply, demand and TCF indicator, for each country.

Table 3. Correlations between HP output gap estimates and output growth components

\begin{tabular}{|c|c|c|c|c|c|c|c|c|c|}
\hline & $\begin{array}{c}\text { Argentina } \\
\text { ygap }\end{array}$ & $\begin{array}{c}\text { Brazil } \\
\text { ygap }\end{array}$ & $\begin{array}{l}\text { Chile } \\
\text { ygap }\end{array}$ & $\begin{array}{c}\text { Colombia } \\
\text { ygap }\end{array}$ & $\begin{array}{c}\text { Mexico } \\
\text { ygap }\end{array}$ & $\begin{array}{l}\text { Peru } \\
\text { ygap }\end{array}$ & $\begin{array}{l}\text { USA } \\
\text { ygap }\end{array}$ & $\begin{array}{c}\text { Venezuela } \\
\text { ygap }\end{array}$ & $\begin{array}{c}\text { Average } \\
\text { correlation }\end{array}$ \\
\hline ys & 0.764 & 0.566 & 0.376 & 0.506 & 0.691 & 0.470 & 0.613 & 0.685 & 0.584 \\
\hline $\operatorname{Pr}($ corr $=0)$ & 0.000 & 0.000 & 0.000 & 0.000 & 0.000 & 0.000 & 0.000 & 0.000 & \\
\hline yd & 0.599 & 0.767 & 0.834 & 0.696 & 0.780 & 0.687 & 0.602 & 0.578 & 0.693 \\
\hline $\operatorname{Pr}($ corr $=0)$ & 0.000 & 0.000 & 0.000 & 0.000 & 0.000 & 0.000 & 0.000 & 0.000 & \\
\hline TCF & 0.880 & 0.957 & 0.914 & 0.791 & 0.931 & 0.854 & 0.823 & 0.856 & 0.876 \\
\hline $\operatorname{Pr}($ corr $=0)$ & 0.000 & 0.000 & 0.000 & 0.000 & 0.000 & 0.000 & 0.000 & 0.000 & \\
\hline
\end{tabular}

In table 3, we can observe that the HP output gap estimates are more correlated to the TCF indicators than to any of their components, signifying that output gaps constitute better proxies for cyclical fluctuations than for demand pressures. Another way to interpret these results is that output gaps contain information on both, demand and supply shocks. Therefore, if HP gaps were used in regressions as excess demand proxies, major biases in regression coefficients could be introduced, depending on particular country-case.

Another issue raised in section 3 is that identification of supply and demand shocks using the Blanchard-Quah methodology could distort the interpretation of fluctuations because of two reasons: it focuses identification on long-run restrictions, and, it neglects price information from the SVAR. To ponder this claim, we compare the output components of our methodology with the output components obtained from two additional types of historical decompositions: one, from the original Blanchard-Quah set-up (BQ_U suffix), that uses longrun restrictions in a SVAR of output growth and unemployment, and the second one from using long-run restrictions in a SVAR of output growth and inflation (BQ_P suffix). ${ }^{22}$ We compare these components by estimating simple pairwise correlations. Results for each country are shown in table 4.

On average, very high correlations are exhibited between the supply component computed according to our framework $\left(\mathrm{y}^{\mathrm{s}}\right)$ and the supply

\footnotetext{
21 Otherwise, the decompositions obtained according to our methodology could be transformed in levels to make them comparable to conventional (level) output gap estimates. However, this is a somehow arbitrary decision.

22 It should be noted that, when applying long-run restrictions, historical decompositions are still computed with the matrix that factorizes the covariance matrix of reduced residuals, i.e. the matrix that contains short-run responses to structural shocks.
} 
component $\mathrm{y}^{\mathrm{s}}(\mathrm{BQ}$ P). For several countries, such as Chile, Peru, United States and Venezuela, this correlation is even very close to one, indicating that, substituting unemployment for prices, while keeping long-run restrictions, provides a good approximation for obtaining our supply component. A clear exception is Argentina that shows a very low correlation (0.31) for the supply component. For the demand component, correlations between $\mathrm{y}^{\mathrm{d}}$ and $\mathrm{y}^{\mathrm{d}}\left(\mathrm{BQ} \_\mathrm{P}\right)$ have more variability, but stay high for those same countries (Chile, Peru, United States and Venezuela). For Argentina and Brazil instead, correlations are very low or negative. Coincidently with this information, in table 2, Argentina and Brazil are the countries where a large portion of the long-term output variance is explained by demand shocks. These results mean that the long-run restriction imposed on the demand shock is misleading for those countries that display persistent demand shocks' effects. These findings are consistent with those of Keating (2013), but for very recent data. Overall, this also means that short-run identification is more encompassing than longrun identification.

On the other hand, the correlations between the output growth components proposed in this paper $\left(\mathrm{y}^{\mathrm{s}}\right.$ and $\left.\mathrm{y}^{\mathrm{d}}\right)$ and the components obtained from the original Blanchard-Quah set-up, $\mathrm{y}^{\mathrm{S}}\left(\mathrm{BQ} \_\mathrm{U}\right)$ and $\mathrm{y}^{\mathrm{d}}\left(\mathrm{BQ} \_\mathrm{U}\right)$, are the lowest, on average: 0.37 against 0.83 for the supply component, and 0.53 against 0.69 for the demand component. This indicates that the original Blanchard-Quah set-up produces the most dissimilar results with respect to our methodology. This also implies that the additional reduction in correlations is due to the use of unemployment information.

In general, this exercise suggests that employing the original Blanchard-Quah set-up introduces important biases in the identification of shocks and components. Based on average correlations, it seems that ignoring the behavior of prices brings about more distortions than using long-run restrictions on an output-price VAR.$^{23}$ Generally speaking, it would seem that the exploitation of price information becomes vital when identifying structural supply and demand shocks.

\footnotetext{
${ }^{23}$ Although, it may also be the case that in countries such as Brazil, researches might prefer using unemployment with long-run identification: to minimize errors in the demand component at the cost of less precision in the supply component.
} 
Table 4. Correlations among historical components using different SVAR methodologies

\begin{tabular}{|c|c|c|c|c|c|}
\hline & & ys (BQ_P) & ys(BQ_U) & yd (BQ_P) & $\mathrm{yd}\left(\mathrm{BQ} \_\mathrm{U}\right)$ \\
\hline Argentina & $\begin{array}{c}\text { ys } \\
\operatorname{Pr}(\text { corr }=0) \\
\text { yd } \\
\operatorname{Pr}(\text { corr }=0)\end{array}$ & $\begin{array}{l}0.313 \\
0.000\end{array}$ & NA & $\begin{array}{l}0.126 \\
0.108\end{array}$ & NA \\
\hline Brazil & $\begin{array}{c}\text { ys } \\
\operatorname{Pr}(\text { corr }=0) \\
\text { yd } \\
\operatorname{Pr}(\text { corr }=0)\end{array}$ & $\begin{array}{l}0.635 \\
0.000\end{array}$ & $\begin{array}{c}-0.058 \\
0.511\end{array}$ & $\begin{array}{r}-0.115 \\
0.102\end{array}$ & $\begin{array}{l}0.800 \\
0.000\end{array}$ \\
\hline Chile & $\begin{array}{c}\text { ys } \\
\operatorname{Pr}(\text { corr }=0) \\
\text { yd } \\
\operatorname{Pr}(\text { corr }=0)\end{array}$ & $\begin{array}{l}0.946 \\
0.000\end{array}$ & $\begin{array}{l}0.304 \\
0.000\end{array}$ & $\begin{array}{l}0.949 \\
0.000\end{array}$ & $\begin{array}{l}0.459 \\
0.000\end{array}$ \\
\hline Colombia & $\begin{array}{c}\text { ys } \\
\operatorname{Pr}(\text { corr }=0) \\
\text { yd } \\
\operatorname{Pr}(\text { corr }=0)\end{array}$ & $\begin{array}{l}0.868 \\
0.000\end{array}$ & $\begin{array}{l}0.491 \\
0.000\end{array}$ & $\begin{array}{l}0.821 \\
0.000\end{array}$ & $\begin{array}{l}0.558 \\
0.000\end{array}$ \\
\hline Mexico & $\begin{array}{c}\text { ys } \\
\operatorname{Pr}(\text { corr }=0) \\
\text { yd } \\
\operatorname{Pr}(\text { corr }=0)\end{array}$ & $\begin{array}{l}0.886 \\
0.000\end{array}$ & $\begin{array}{l}0.772 \\
0.000\end{array}$ & $\begin{array}{l}0.747 \\
0.000\end{array}$ & $\begin{array}{l}0.671 \\
0.000 \\
\end{array}$ \\
\hline Peru & $\begin{array}{c}\text { ys } \\
\operatorname{Pr}(\text { corr }=0) \\
\text { yd } \\
\operatorname{Pr}(\text { corr }=0)\end{array}$ & $\begin{array}{l}0.999 \\
0.000\end{array}$ & $\begin{array}{l}0.282 \\
0.001\end{array}$ & $\begin{array}{l}0.999 \\
0.000\end{array}$ & $\begin{array}{l}0.563 \\
0.000\end{array}$ \\
\hline USA & $\begin{array}{c}\text { ys } \\
\operatorname{Pr}(\text { corr }=0) \\
\text { yd } \\
\operatorname{Pr}(\text { corr }=0)\end{array}$ & $\begin{array}{l}0.988 \\
0.000\end{array}$ & $\begin{array}{l}0.590 \\
0.000\end{array}$ & $\begin{array}{l}0.967 \\
0.000\end{array}$ & $\begin{array}{l}0.132 \\
0.091\end{array}$ \\
\hline Venezuela & $\begin{array}{c}\text { ys } \\
\operatorname{Pr}(\text { corr }=0) \\
\text { yd } \\
\operatorname{Pr}(\text { corr }=0)\end{array}$ & $\begin{array}{l}0.998 \\
0.000\end{array}$ & $\begin{array}{l}0.239 \\
0.002\end{array}$ & $\begin{array}{l}0.994 \\
0.000\end{array}$ & $\begin{array}{l}0.495 \\
0.000\end{array}$ \\
\hline $\begin{array}{l}\text { Average } \\
\text { correlation }\end{array}$ & & 0.829 & 0.374 & 0.686 & 0.525 \\
\hline
\end{tabular}

$\mathrm{y}^{\mathrm{S}}$ and $\mathrm{y}^{\mathrm{D}}$ : supply and demand components of output growth in a SVAR(y, pi) identified with sign restrictions; $\mathrm{y}^{\mathrm{S}}\left(\mathrm{BQ} \_\mathrm{P}\right)$ and $\mathrm{y}^{\mathrm{D}}(\mathrm{BQ} P \mathrm{P})$ : supply and demand components of output growth in a $\operatorname{SVAR}\left(\mathrm{y}\right.$, pi) identified with long-run restrictions; $\mathrm{y}^{\mathrm{S}}(\mathrm{BQ} \mathrm{U})$ and $\mathrm{y}^{\mathrm{D}}\left(\mathrm{BQ} \_\mathrm{U}\right)$ : supply and demand components of output growth in a $\operatorname{SVAR}(\mathrm{y}, \mathrm{u})$ identified with long-run restrictions; $\mathrm{u}$ : the seasonally adjusted unemployment rate. 


\section{Summary of findings}

It has been argued along this article that policy practitioners have tended to ignore the effects of supply shocks on output fluctuations. In other words, practitioners have somehow neglected the existence of theoretical mechanisms, available in modern New Keynesian DSGE models, which acknowledge that supply shocks can explain a great deal of output and inflation variability. We could speculate about why this has been the case. One reason could be found in the long-run/short-run dichotomy about output behavior (depicted in traditional Keynesian models) that justifies monetary policy interventions at all times. Another possibility is the lack of a fluent communication between rapidly available policy-oriented tools and more complex theoretical models. Nonetheless, independently of the actual reasons, the diagnosis grounded on neglecting the potential effects of supply shocks could distort, at some point, policy evaluations and interventions.

A possible solution to the above problem might lie in the use of more adequate tools for policy analysis, within the framework of already known statistical methodologies that characterize supply and demand shocks, such as Blanchard-Quah. This article suggests the implementation of a more agnostic structural analysis that can provide practitioners with better diagnosis. Instead of identifying disturbances according to their dynamic effects, supply and demand shocks are disentangled according to a more ample notion: their matching effects on output and their opposite effects on prices. Not only has this notion been already applied in the empirical literature, but also constitutes a widely accepted premise that separates changes in firms' decisions and provision of goods from changes in household decisions and demand of goods. Econometrically, this short-run identification strategy is carried out through the imposition of sign restrictions on a bi-variate structural VAR that contains inflation information. Empirically, short-run identification is more encompassing than long-run identification because it does not rule out the possibility that any shock could have a permanent effect either on output or on prices. However, a more pressing issue for ensuring a successful identification of shocks and their effects would be the use of inflation information, even if long-run restrictions are maintained.

The proposal for policy analysis is based on the separation of output growth in its supply and demand components and their combination in two-related measures: total cyclical fluctuation (TCF) and the goods market unbalance (GMU). While the sign of TCF points out whether the actual variable is growing or falling with respect to its long-run value, the GMU denotes a potential conflict between the demand and supply sides of the market. When this last indicator (GMU) takes significant values, it also suggests that inflation is changing markedly and there is room for policy intervention. But depending on the importance of supply shocks for explaining output and unbalances, adjustments in inflation not always call for monetary policy interventions. When the GMU and TCF indicators are jointly interpreted, we can assess whether monetary policy actions are indeed desirable. 
An analysis based on the characterization of TCF and GMU indicators solely represents the starting point of more complex discussions. When policy practitioners ask for the specific drivers of fluctuations, this analysis does not provide the precise answers. But instead, it delivers an initial categorization of factors (supply or demand) that can be more useful for tracking down shocks and transmission mechanisms than traditional output gaps. Ultimately, what should be kept in mind is that the interpretation of events through statistical models should be informative, but without imposing visions that are too narrow. This article tries to point exactly in this direction.

\section{References}

Basu, S. (1995). Intermediate Goods and Business Cycles: Implications for Productivity and Welfare. American Economic Review, 85(3), 512-531.

Basu, S., \& Fernald, J. G. (2009). What do we know (and not know) about potential output? Federal Reserve Bank of St. Louis Review, 91(July/August 2009).

Blanchard, O. J., \& Quah, D. (1989). The Dynamic Effects of Aggregate Demand and Supply Disturbances. The American Economic Review, 79(4), 655-673. doi: 10.2307/1827924

Buch, C. M., Eickmeier, S., \& Prieto, E. (2014). Macroeconomic Factors and Microlevel Bank Behavior. Journal of Money, Credit and Banking, 46(4), 715-751. doi: 10.1111/jmcb.12123

Canova, F., \& Nicoló, G. D. (2002). Monetary disturbances matter for business fluctuations in the G-7. Journal of Monetary Economics, 49(6), 1131-1159.

Clarida, R., \& Gali, J. (1994). Sources of real exchange-rate fluctuations: How important are nominal shocks? Paper presented at the CarnegieRochester Conference Series on Public Policy.

Eickmeier, S., \& Hofmann, B. (2013). Monetary policy, housing booms, and financial [im] balances. Macroeconomic dynamics, 17(4), 830-860. doi: dx.doi.org/10.1017/S1365100511000721

Eickmeier, S., Hofmann, B., \& Worms, A. (2009). Macroeconomic fluctuations and bank lending: evidence for Germany and the euro rea. German Economic Review, 10(2), 193-223.

Fernández-Villaverde, J., Guerrón-Quintana, P., Kuester, K., \& RubioRamírez, J. (2015). Fiscal Volatility Shocks and Economic Activity. American Economic Review, 105(11), 3352-3384. doi: 10.1257/aer.20121236

Fisher, L. A., Huh, H. S., \& Pagan, A. R. (2015). Econometric Methods for Modelling Systems with a Mixture of I (1) and I (0) variables. Journal of Applied Econometrics.

Fry, R., \& Pagan, A. (2011). Sign restrictions in structural vector autoregressions: a critical review. Journal of Economic Literature, 49(4), 938-960.

Fuentes, R., Gredig, F., \& Larraín, M. (2008). La brecha de producto en Chile: medición y evaluación. Economía Chilena, 11(2), 7-30. 
Gopinath, G., \& Neiman, B. (2014). Trade Adjustment and Productivity in Large Crises. American Economic Review, 104(3), 793-831. doi: 10.1257/aer.104.3.793

Halpern, L., Koren, M., \& Szeidl, A. (2015). Imported Inputs and Productivity. American Economic Review, 105(12), 3660-3703. doi: 10.1257/aer.20150443

Keating, J. W. (2013). What Do We Learn from Blanchard and Quah Decompositions of Output If Aggregate Demand May Not Be LongRun Neutral? Journal of Macroeconomics, 38(part B), 203-217. doi: 10.1016/j.jmacro.2013.07.007

Mumtaz, H., \& Surico, P. (2009). The Transmission of International Shocks: A Factor-Augmented VAR Approach. Journal of Money, Credit, and Banking, 41(s1), 71-100. doi: 10.1111/j.1538-4616.2008.00199.x

Rubio-Ramírez, J. F., Waggoner, D. F., \& Zha, T. A. O. (2010). Structural Vector Autoregressions: Theory of Identification and Algorithms for Inference. Review of Economic Studies, 77(2), 665-696. doi: 10.1111/j.1467-937X.2009.00578.x

Uhlig, H. (2005). What are the effects of monetary policy on output? Results from an agnostic identification procedure. Journal of Monetary Economics, 52(2), 381-419. 


\section{CENTER FOR LATIN AMERICAN MONETARY STUDIES}

Regional Association of Central Banks

www.cemla.org

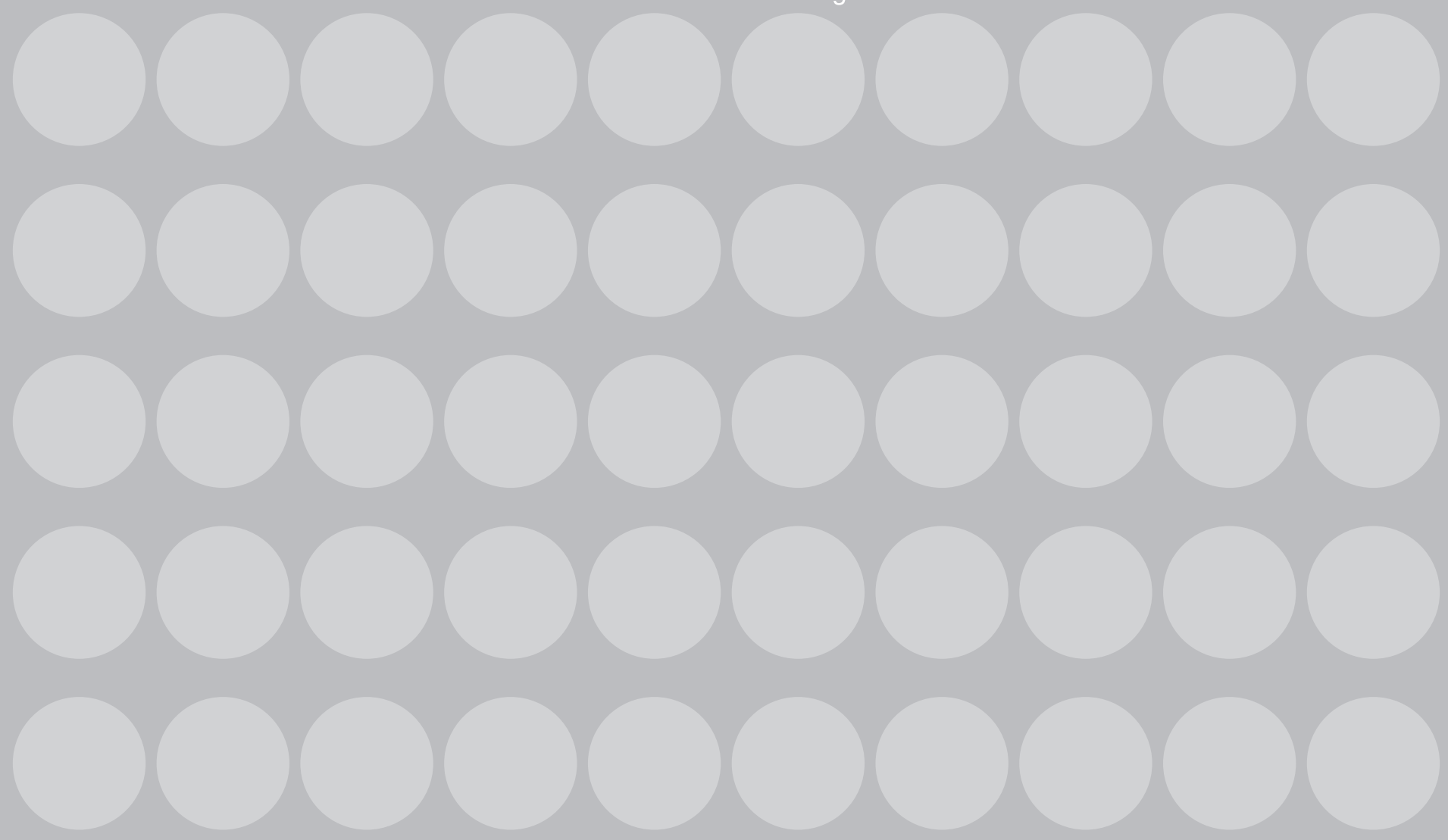

